\title{
Review
}

Cerebrovascular Diseases
Cerebrovasc Dis 2014;38:233-239

DOI: $10.1159 / 000368887$
Received: September 25, 2014

Accepted: October 6, 2014

Published online: November 13, 2014

\section{How Can You Mend a Broken Brain? - Neurorestorative Approaches to Stroke Recovery}

\author{
Dale Corbett ${ }^{a-d}$ Carine Nguemeni ${ }^{\mathrm{a}, \mathrm{b}}$ Mariana Gomez-Smith ${ }^{\mathrm{a}, \mathrm{b}}$ \\ ${ }^{a}$ Department of Cellular \& Molecular Medicine, Faculty of Medicine, ${ }^{b}$ Canadian Partnership for Stroke Recovery, \\ University of Ottawa, Ottawa, Ont., 'Faculty of Medicine, Memorial University of Newfoundland, St. John's, Nfld., \\ and ${ }^{d}$ Faculty of Medicine, University of Toronto, Toronto, Ont., Canada
}

\section{Key Words}

Stroke recovery $\cdot$ Neuroplasticity $\cdot$ Enriched rehabilitation .

Functional outcome

\begin{abstract}
Background: Stroke is a devastating disorder that strikes approximately 15 million people worldwide. While most patients survive stroke, many are left with lifelong impairments, thereby making stroke the leading cause of permanent neurological disability. Despite this, there are a few options for treatment of acute stroke. Restoration of blood flow using clot-dissolving drugs has produced impressive benefits in some patients. However, for these drugs to be effective, they must be given soon after stroke onset and relatively only a few stroke patients reach hospital within this time. Side effects of these compounds further limit their use. Summary: Enhancing the brain's endogenous capacity for reorganization and self-repair offers the most promise for victims of stroke. Indeed, many stroke patients show considerable spontaneous functional improvement. Findings in the last 15 years suggest that stroke and related injury create a cerebral milieu similar to that of early brain development, a period characterized by rapid neuronal growth and neuroplasticity. A variety of interventions (e.g., stem cells, delivery of growth factors) are currently being explored in order to en-
\end{abstract}

hance neuroplasticity and reorganizational processes that are important for recovery of function. An emerging concept is that combinational or 'cocktail' therapies are more effective than single interventions in improving stroke recovery. Among these, one of the most promising therapies is enriched rehabilitation, a combination of environmental enrichment and task-specific therapy (e.g., reach training). Key Messages: Neurorestorative approaches to brain reorganization and repair are providing new insights into how neural circuits respond to injury and how this knowledge can be used for optimizing stroke rehabilitation practice.

(c) 2014 S. Karger AG, Basel

\section{Introduction}

Stroke is the leading cause of adult neurological disability and the second leading cause of death worldwide. Attempts to reduce the incidence of stroke are being countered by an aging population and rising rates of obesity and metabolic disturbances as a result of a sedentary lifestyle and poor diet [1]. Despite significant advances in our understanding of the pathophysiology of stroke, all neuroprotective drug trials failed leaving t-PA as the only effective treatment for acute stroke [2]. Unfortunately, the limited time window and side effects limit its use to a

\section{KARGER}

E-Mail karger@karger.com

www.karger.com/ced (c) 2014 S. Karger AG, Base

$1015-9770 / 14 / 0384-0233 \$ 39.50 / 0$
Dale Corbett, $\mathrm{PhD}$

Department of Cellular \& Molecular Medicine, Faculty of Medicine Roger Guindon Hall, 3510G, University of Ottawa 451 Smyth Rd., Ottawa, ON, K1H 8M5 (Canada)

E-Mail dcorbett@uottawa.ca 
relatively small percentage of stroke patients [3]. Furthermore, many patients benefitting from t-PA are still left with significant disabilities. In recent years, research in the stroke field has begun to shift from acute stroke to the stroke recovery phase. This change in emphasis has been triggered by a dramatic increase in our understanding of neuroplasticity and its potential to reorganize and restore function to the stroke-damaged brain $[4-8,26]$. Clearly, neurorestorative interventions, including rehabilitation, offer the most hope for stroke survivors because the therapeutic time window is not limited to minutes to hours, as for t-PA, but instead applicable to weeks, months, and years and can be applied to any type of stroke, including hemorrhagic stroke.

\section{Modeling Stroke Recovery}

An important lesson from the failed stroke neuroprotection trials is that preclinical models, while never perfectly mimicking human stroke, must nonetheless capture essential features of the disease in order to avoid generating false positive results with subsequent translational failure [9-11]. For example, most stroke patients have residual deficits even years after their injury [12]. Thus, it is essential to develop animal models that also produce similar chronic functional deficits. An increasingly popular model uses endothelin-1 (ET-1), which when stereotaxically injected induces vasoconstriction followed by a gradual reperfusion, similar to human ischemic stroke [13]. The ensuing long-lasting, sensory-motor deficits make it ideal for stroke recovery studies. In addition to choosing an appropriate stroke model, it is essential to employ a sensitive battery of sensory-motor tests since recovery on one test does not guarantee recovery on other tests. Impairment of the upper limb after stroke is very common and the deficits are often persistent [14]. Therefore, a reaching task should be part of any rodent behavioral test battery to assess stroke recovery. Particularly useful, due to their great sensitivity and clinical relevance, are tests of skilled reaching such as the Montoya staircase or single pellet reaching test [4, 14-17].

\section{Stroke Rehabilitation - Missed Opportunities?}

An emerging view of the last 15 years is that stroke recreates a cerebral milieu similar to that of early brain development, a period characterized by rapid brain growth and remodeling of synaptic connections. The adult brain re- sponds to stroke by increasing dendritic growth, forming new synapses, reorganizing functional maps, and by upregulating growth factors $[6,18-20]-$ all processes thought to contribute to behavioral recovery. Complex changes in growth-promoting and growth-inhibitory genes have been revealed following cortical stroke in rats [20,21]. The general pattern is that growth inhibitory proteins (e.g., Nogo) are inhibited for several weeks after stroke but thereafter begin to show increased expression. Conversely, growthpromoting genes, including Gap-43, are highly expressed in the first days after stroke. This pattern of post-stroke gene expression is suggestive of a 'permissive neural niche' for stroke recovery in the first few weeks after injury [20]. While the experience of stroke patients varies considerably depending on injury severity, disease comorbidity, staffing, and resource issues, it is the case that in the first few weeks after stroke, many patients are alone as much as $60 \%$ of their time and inactive during $75 \%$ of their waking hours [22]. Except for the period allocated for therapy sessions, the lack of stimulation, exercise, and socialization is striking. Further, current rehabilitation practice is often not early, nor intense, and most clinical trials are conducted in the chronic phase (i.e., $>6$ months) of stroke recovery [23].

\section{Enriched Rehabilitation and Stroke Recovery}

Many of the reparative gene programs initiated by stroke are profoundly affected by behavioral and environmental experience, such as housing animals in enriched environments (large cages with novel objects to provide exercise, sensory-motor, social and cognitive stimulation) or providing running exercise $[24,27,28]$. For example, environmental enrichment, like exercise, increases levels of growth factors, neurogenesis, and angiogenesis [28-31]. While many studies have shown that environmental enrichment improves motor recovery after stroke [27], the benefits are primarily seen on gross tests of sensory-motor function such as rotarod or neurologic test batteries and not tests of reaching that require fine motor skills $[4,32]$. Accordingly, we developed a rehabilitation paradigm, termed enriched rehabilitation (ER) that combines the social, sensory-motor, and cognitive stimulation inherent to environmental enrichment with daily reach training in order to provide task-specific therapy of the affected limb, following forelimb cortical stroke in rats (fig. 1a-c). This paradigm has been successfully used to improve recovery of skilled reaching in rats following different forms of ischemic and hemorrhagic stroke [33-35]. 

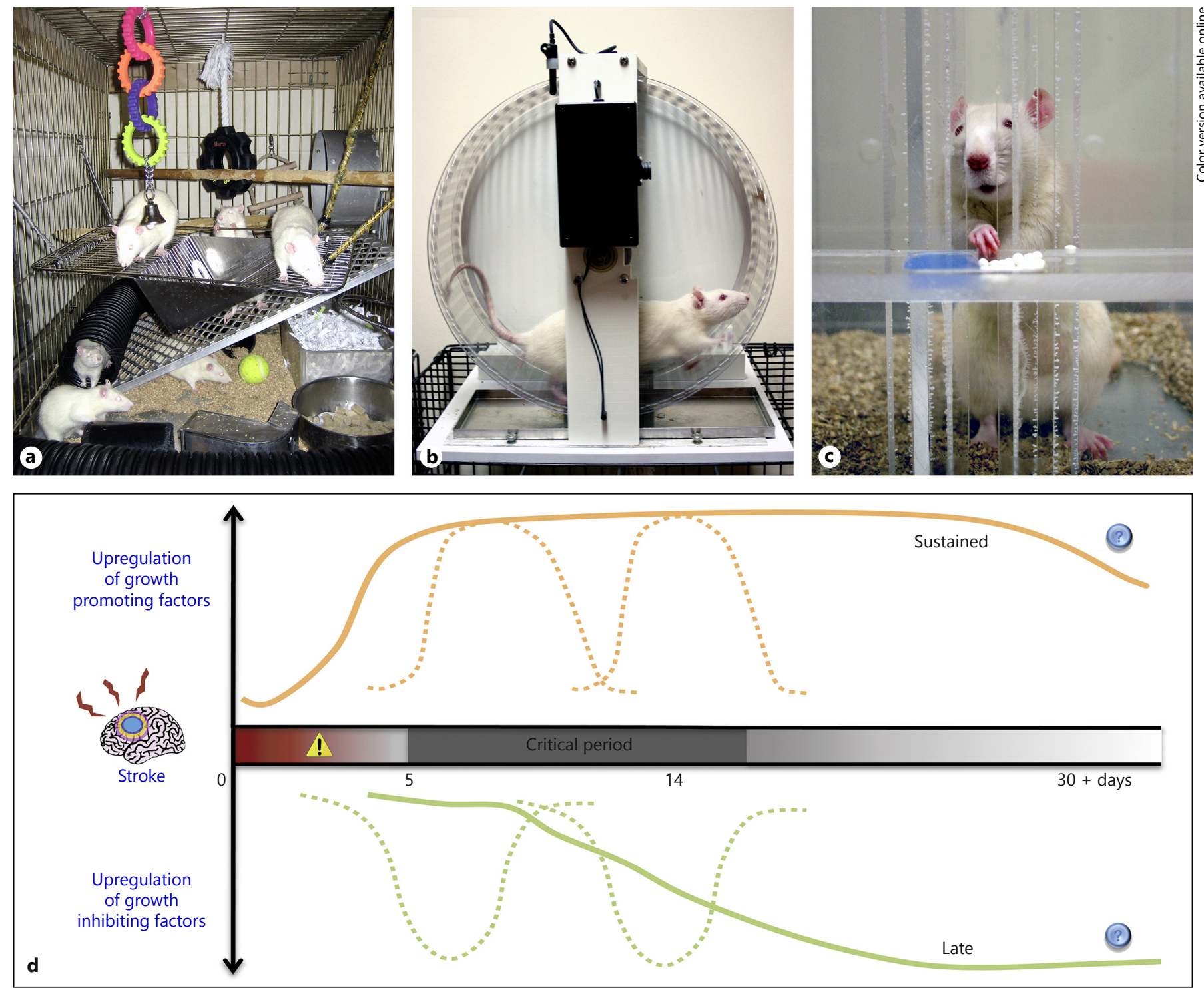

Fig. 1. Enriched rehabilitation paradigm and the critical period of post-stroke rehabilitation. After stroke, skilled use of the affected hand (or paw) is highly resistant to recovery in both humans and animals. In rats, enriched rehabilitation produces substantial improvements in the recovery of skilled reaching [25, 34-36, 67]. The protocol consists of enriched housing (a) and/or running exercise (b) in combination with several hours of daily reach training (c) of the impaired limb. Rats are housed in enriched environments starting 5-14 days after stroke (d). The timing of rehabilitation is designed to optimally engage neuroplasticity processes during the critical period of the early post-stroke recovery phase, during which a sustained upregulation of growthpromoting genes predominates (solid red line in part d). Most growth-inhibitory genes (solid green line) tend to be upregulated gradually, several weeks after stroke, toward the end of the critical period of stroke recovery. A few growth-promoting and growthinhibiting genes are transiently upregulated (dashed lines) in the early and mid post-stroke recovery period. This critical period is observed in animal studies and might be different in the case of human stroke, where spontaneous recovery can extend for the first 90 days after injury. Data in part $\mathbf{d}$ is adapted from [20, 21]. Figure modified from [4]. 


\section{Rehabilitation: Timing and the Concept of Critical Periods}

In addition to improving behavioral recovery, a key effect of ER is that it increases dendritic length and complexity of layer $\mathrm{V}$ motor neurons in the stroke-damaged brain [25], suggesting that this structural modification may be contributing to the improved outcome. In support of this notion are animal studies showing that delayed initiation of ER until 30 days after stroke does not result in improved functional recovery nor does it alter layer $\mathrm{V}$ dendrites. These findings suggest there is 'critical or sensitive period' lasting several weeks after stroke when brain plasticity processes (fig. 1d) are optimally responsive to rehabilitation $[4,36]$. Interestingly, this critical period coincides with the rising waves of growth-promoting genes that appear to peak 30 days after stroke [20]. While there is general consensus that post-stroke rehabilitation should be started sooner rather than later, there is no agreement as to exactly when it should start or when it is too late to achieve substantial benefit $[23,37,38]$. Animal studies, including some of our own research $[4,23,36]$, have helped guide clinical studies including the recent EXPLICIT stroke trial evaluating early constraint-induced movement therapy [39], although an earlier constraint therapy study reported negative [40] outcomes. However, results may be influenced not only by timing, but also by the type and intensity of the intervention since early aphasia therapy [41] and early physical activity [42, 43] are associated with better outcomes.

\section{Brain Derived Neurotrophic Factor and Stroke Recovery}

Brain Derived Neurotrophic Factor (BDNF) is the most highly expressed growth factor in the human brain and plays an essential role in neuroplasticity in both the intact and the damaged brain by increasing neuronal survival, synaptogenesis, angiogenesis, and neurogenesis [44]. Administration of BDNF in shortly after stroke reduces injury [45], whereas delayed administration is associated with improved sensory-motor recovery $[46,47]$. Our laboratory has investigated the possible role of BDNF in mediating the behavioral recovery induced by rehabilitation. Notably, blocking BDNF in the rat negates the benefits of rehabilitation-induced recovery after sensorymotor cortex stroke [48], while selective blockade of BDNF signaling in the peri-infarct cortex attenuates glutamate, AMPAR-mediated spontaneous motor recovery in mice subjected to photothrombotic stroke [49]. In related work [34], it was found that a critical amount or 'threshold' of post-stroke reaching rehabilitation must be met to obtain functional recovery. Animals exceeding this threshold exhibited forelimb recovery and showed significant increases in motor cortex BDNF levels, while rats receiving less rehabilitation did not recover and BDNF levels remained at control levels. These findings clearly indicate that BDNF plays a key role in post-stroke rehabilitation and consequently BDNF may be an important target to enhance recovery in stroke patients.

\section{Stem Cells and Stroke Recovery}

The identification of at least two neurogenic zones in the rodent and human brain created optimism for brain repair and stroke recovery because neural stem cells and their progenitors, collectively termed neural precursor cells (NPCs), were observed to migrate toward an injury site [50-52]. Direct delivery of NPCs [53-56] or mobilization of endogenous NPCs with growth factors or drugs $[57,58]$ improves recovery after stroke but in most of these studies, the behavioral effects are rather small. Mesenchymal stem cells appear to be especially effective in restoring function after focal stroke. Indeed, in one recent review, it was noted that approximately $95 \%$ of studies reported improved functional outcomes [59]. However, similar impressive outcomes were noted in early neuroprotection reviews, so a more cautious and critical assessment of stem cell studies is clearly warranted. For example, many of the mesenchymal stem cell studies used rather crude neurological test scores and simple balance tests that tend to resolve rather quickly without intervention [4]. Thus, it will be important to demonstrate that stem cell therapies are effective with more demanding behavioral tests where spontaneous recovery is limited.

\section{New Approaches to Brain Repair - Combination Therapies}

Increasing evidence indicates that the causes of ischemic cell death are multi-factorial [3]. Furthermore, the brain responds to vascular insults by marshalling a wide array of self-protective mechanisms $[3,60]$ that stand in marked contrast to the single-target approach commonly employed in neuroprotection [61]. When interventions (e.g., hypothermia) target multiple, instead of single mechanisms, the results are impressive $[3,62]$. Similarly, 
a more effective approach might be to use a 'cocktail' intervention to exploit multiple complementary neuroplastic mechanisms to restore post-stroke recovery. For example, each of the individual elements of enriched rehabilitation (exercise, socialization, cognitive stimulation, reach training) has some therapeutic potential but collectively provide a powerful intervention by acting upon multiple complementary processes of neuroplasticity (e.g., upregulation of growth factors, angiogenesis, dendritic sprouting) [27, 63]. This was illustrated in a recent experiment showing that ER, but not enriched environments or reach training alone, strongly activated neurons in layer II and III peri-infarct cortex [64], a region thought to be critical for recovery of sensory-motor function [4, $65,66]$. These findings indicate that a combination of environmental enrichment and task-specific rehabilitation targeting the main functional deficit (i.e., skilled reaching) most effectively increases neuronal activity around the lesion. Similarly, in more recent work, we found that serial administration of epidermal growth factor and erythropoietin induced mobilization of the endogenous NPC pool and resulted in significantly faster and more complete recovery after cortical stroke in rats when it was combined with ER [67]. This is the first demonstration that stem cell therapy produces an additive benefit in stroke recovery beyond what can be achieved with an optimized rehabilitation paradigm. This is important because stem cell therapies (or other interventions) will likely not be employed unless they provide benefit in beyond what is already achieved through current best practice (i.e., rehabilitation).

Designing preclinical and clinical studies using combination therapies is more complicated and costly than traditional single intervention studies. Nonetheless, the efficacy of single interventions in stroke is abysmal and sooner or later, this 'silver bullet' approach must be abandoned [3]. Adapting preclinical enrichment paradigms to the clinic is possible and early results with enriched rehabilitation in stroke patients are encouraging [68]. Clearly the post-stroke environment has the potential to significantly impact the brain's intrinsic restorative programs and in so doing profoundly affect stroke recovery. Indeed, enriched rehabilitation, unlike many other preclinical post-stroke interventions, has shown consistent benefits across laboratories and stroke models [25, 35, 69].

\section{Funding}

Operating grants from the Canadian Institutes for Health Research (CIHR), the Heart and Stroke Foundation of Canada and the Canadian Stroke Network to DC are gratefully acknowledged. D. Corbett was the recipient of a Tier 1 Canada Research Chair in Stroke and Neuroplasticity.

\section{Disclosure Statement}

No conflicts of interest.

\section{Ethics}

All research conducted by the authors described in this article conformed to the guidelines established by the Canadian Council on Animal Care and were approved by the institutional animal care committees of Memorial University of Newfoundland and the University of Ottawa.

\section{References}

1 Feigin VL, Forouzanfar MH, Krishnamurthi R, Mensah GA, Connor M, Bennett DA, Moran AE, Sacco RL, Anderson L, Truelsen T, O'Donnell M, Venketasubramanian N, Barker-Collo S, Lawes CM, Wang W, Shinohara Y, Witt E, Ezzati M, Naghavi M, Murray C: Global and regional burden of stroke during 1990-2010: findings from the global burden of disease study 2010. Lancet 2014;383:245254.

-2 O'Collins VE, Macleod MR, Donnan GA, Horky LL, van der Worp BH, Howells DW: 1,026 experimental treatments in acute stroke. Ann Neurol 2006;59:467-477.

3 Iadecola C, Anrather J: Stroke research at a crossroad: asking the brain for directions. Nat Neurosci 2011;14:1363-1368.
4 Murphy TH, Corbett D: Plasticity during stroke recovery: from synapse to behaviour. Nat Rev Neurosci 2009;10:861-872.

5 Nudo RJ, Wise BM, SiFuentes F, Milliken GW: Neural substrates for the effects of rehabilitative training on motor recovery after ischemic infarct. Science 1996;272:1791-1794.

6 Nudo RJ: Postinfarct cortical plasticity and behavioral recovery. Stroke 2007;38:840-845.

7 Dancause N, Nudo RJ: Shaping plasticity to enhance recovery after injury. Prog Brain Res 2011;192:273-295.

-8 Carmichael ST, Krakauer JW: The promise of neuro-recovery after stroke: introduction. Stroke 2013;44(6 suppl 1):S103.

-9 Fisher M, Feuerstein G, Howells DW, Hurn PD, Kent TA, Savitz SI, Lo EH; STAIR Group:
Update of the stroke therapy academic industry roundtable preclinical recommendations. Stroke 2009;40:2244-2250.

10 Dirnagl U, Lauritzen M: Improving the quality of biomedical research: guidelines for reporting experiments involving animals. J Cereb Blood Flow Metab 2011;31:989-990.

11 Dirnagl U: Bench to bedside: the quest for quality in experimental stroke research. J Cereb Blood Flow Metab 2006;26:1465-1478.

12 Dobkin BH: Clinical practice. Rehabilitation after stroke. N Engl J Med 2005;352:1677-1684.

13 Windle V, Szymanska A, Granter-Button S, White C, Buist R, Peeling J, Corbett D: An analysis of four different methods of producing focal cerebral ischemia with endothelin-1 in the rat. Exp Neurol 2006;201:324-334. 
14 Wade DT, Wood VA, Hewer RL: Recovery after stroke - the first 3 months. J Neurol Neurosurg Psychiatry 1985;48:7-13.

$\checkmark 15$ Iwaniuk AN, Whishaw IQ: On the origin of skilled forelimb movements. Trends Neurosci 2000;23:372-376.

$\checkmark 16$ Bury SD, Jones TA: Unilateral sensorimotor cortex lesions in adult rats facilitate motor skill learning with the 'Unaffected' forelimb and training-induced dendritic structural plasticity in the motor cortex. J Neurosci 2002;22:8597-8606.

17 Maldonado MA, Allred RP, Felthauser EL, Jones TA: Motor skill training, but not voluntary exercise, improves skilled reaching after unilateral ischemic lesions of the sensorimotor cortex in rats. Neurorehabil Neural Repair 2008;22:250-261.

18 Cramer SC, Chopp M: Recovery recapitulates ontogeny. Trends Neurosci 2000;23:265-271.

-19 Jones TA, Chu CJ, Grande LA, Gregory AD: Motor skills training enhances lesion-induced structural plasticity in the motor cortex of adult rats. J Neurosci 1999;19:1015310163.

20 Carmichael ST, Archibeque I, Luke L, Nolan T, Momiy J, Li S: Growth-associated gene expression after stroke: evidence for a growthpromoting region in peri-infarct cortex. Exp Neurol 2005;193:291-311.

-21 Li S, Carmichael ST: Growth-associated gene and protein expression in the region of axonal sprouting in the aged brain after stroke. Neurobiol Dis 2006;23:362-373.

-22 Bernhardt J, Dewey H, Thrift A, Donnan G: Inactive and alone: physical activity within the first 14 days of acute stroke unit care. Stroke 2004;35:1005-1009.

$\checkmark 23$ Krakauer JW, Carmichael ST, Corbett D, Wittenberg GF: Getting neurorehabilitation right: what can be learned from animal models? Neurorehabil Neural Repair 2012;26: 923-931.

-24 Kolb B, Forgie M, Gibb R, Gorny G, Rowntree $S$ : Age, experience and the changing brain. Neurosci Biobehav Rev 1998;22:143-159.

25 Biernaskie J, Corbett D: Enriched rehabilitative training promotes improved forelimb motor function and enhanced dendritic growth after focal ischemic injury. J Neurosci 2001;21:5272-5280.

26 Dancause N, Barbay S, Frost SB, Plautz EJ, Chen D, Zoubina EV, Stowe AM, Nudo RJ: Extensive cortical rewiring after brain injury. J Neurosci 2005;25:10167-10179.

-27 Will B, Galani R, Kelche C, Rosenzweig MR: Recovery from brain injury in animals: relative efficacy of environmental enrichment, physical exercise or formal training (19902002). Prog Neurobiol 2004;72:167-182.

-28 Swain RA, Harris AB, Wiener EC, Dutka MV, Morris HD, Theien BE, Konda S, Engberg K, Lauterbur PC, Greenough WT: Prolonged exercise induces angiogenesis and increases cerebral blood volume in primary motor cortex of the rat. Neuroscience 2003; 117:1037-1046.
29 Cotman CW, Berchtold NC, Christie LA: Exercise builds brain health: key roles of growth factor cascades and inflammation. Trends Neurosci 2007;30:464-472.

30 Kleim JA, Cooper NR, Vandenberg PM: Exercise induces angiogenesis but does not alter movement representations within rat motor cortex. Brain Res 2002;934:1-6.

31 van Praag H, Christie BR, Sejnowski TJ, Gage FH: Running enhances neurogenesis, learning and long term potentiation. Proc Natl Acad Sci U S A 1999;96:13427-13431.

32 Grabowski M, Brundkin P, Johansson BB: Paw-reaching, sensorimotor, and rotational behavior after brain infarction in rats. Stroke 1993;24:889-895.

33 Biernaskie J, Corbett D, Peeling J, Wells J, Lei $\mathrm{H}$ : A serial MR study of cerebral blood flow changes and lesion development following endothelin-1-induced ischemia in rats. Magn Reson Med 2001;46:827-830.

34 MacLellan CL, Keough MB, Granter-Button S, Chernenko GA, Butt S, Corbett D: A critical threshold of rehabilitation involving brainderived neurotrophic factor is required for poststroke recovery. Neurorehabil Neural Repair 2011;25:740-748.

35 Caliaperumal J, Colbourne F: Rehabilitation improves behavioral recovery and lessens cell death without affecting iron, ferritin, transferrin, or inflammation after intracerebral hemorrhage in rats. Neurorehabil Neural Repair 2014;28:395-404.

-36 Biernaskie J, Chernenko G, Corbett D: Efficacy of rehabilitative experience declines with time after focal ischemic brain injury. J Neurosci 2004;24:1245-1254.

-37 Korner-Bitensky N: When does stroke rehabilitation end? Int J Stroke 2013;8:8-10.

38 Bernhardt J, Indredavik B, Langhorne P: When should rehabilitation begin after stroke? Int J Stroke 2013;8:5-7.

-39 Nijland RH, van Wegen EE, Harmeling-van der Wel BC, Kwakkel G: Accuracy of physical therapists' early predictions of upper-limb function in hospital stroke units: the EPOS Study. Phys Ther 2013;93:460-469.

40 Dromerick AW, Lang CE, Birkenmeier RL, Wagner JM, Miller JP, Videen TO, Powers WJ, Wolf SL, Edwards DF: Very Early Constraint-Induced Movement during Stroke Rehabilitation (VECTORS): A single-center RCT. Neurology 2009;73:195-201.

41 Godecke E, Ciccone NA, Granger AS, Rai T, West D, Cream A, Cartwright J, Hankey GJ: A comparison of aphasia therapy outcomes before and after a very early rehabilitation programme following stroke. Int $J$ Lang Commun Disord 2014;49:149-161.

42 West T, Churilov L, Bernhardt J: Early physical activity and discharge destination after stroke: a comparison of acute and comprehensive stroke unit care. Rehabil Res Pract 2013;2013:498014.

43 Askim T, Bernhardt J, Salvesen O, Indredavik B: Physical activity early after stroke and its association to functional outcome 3 months later. J Stroke Cerebrovasc Dis 2014;23:e305e312. DOI: 10.1016/j.jstrokecerebrovasdis. 2013.12.011. Epub 2014.

44 Park H, Poo MM: Neurotrophin regulation of neural circuit development and function. Nat Rev Neurosci 2013;14:7-23.

45 Schabitz WR, Sommer C, Zoder W, Kiessling $\mathrm{M}$, Schwaninger M, Schwab S: Intravenous brain-derived neurotrophic factor reduces infarct size and counterregulates Bax and Bcl-2 expression after temporary focal cerebral ischemia. Stroke 2000;31:2212-2217.

46 Schabitz WR, Berger C, Kollmar R, Seitz M, Tanay E, Kiessling M, Schwab S, Sommer C: Effect of brain-derived neurotrophic factor treatment and forced arm use on functional motor recovery after small cortical ischemia. Stroke 2004;35:992-997.

47 Schabitz WR, Steigleder T, Cooper-Kuhn CM, Schwab S, Sommer C, Schneider A, Kuhn HG: Intravenous brain-derived neurotrophic factor enhances poststroke sensorimotor recovery and stimulates neurogenesis. Stroke 2007;38:2165-2172.

48 Ploughman M, Windle V, MacLellan CL, White C, Dore JJ, Corbett D: Brain-derived neurotrophic factor contributes to recovery of skilled reaching after focal ischemia in rats. Stroke 2009;40:1490-1495.

49 Clarkson AN, Overman JJ, Zhong S, Mueller R, Lynch G, Carmichael ST: AMPA receptorinduced local brain-derived neurotrophic factor signaling mediates motor recovery after stroke. J Neurosci 2011;31:3766-3775.

50 Chen J, Li Y, Wang L, Zhang Z, Lu D, Lu M, Chopp M: Therapeutic benefit of intravenous administration of bone marrow stromal cells after cerebral ischemia in rats. Stroke 2001;32: 1005-1011.

51 Veizovic T, Beech JS, Stroemer RP, Watson WP, Hodges H: Resolution of stroke deficits following contralateral grafts of conditionally immortal neuroepithelial stem cells. Stroke 2001;32:1012-1019.

52 Parent JM, Vexler ZS, Gong C, Derugin N, Ferriero DM: Rat forebrain neurogenesis and striatal neuron replacement after focal stroke. Ann Neurol 2002;52:802-813.

53 Zhao LR, Duan WM, Reyes M, Keene CD, Verfaillie CM, Low WC: Human bone marrow stem cells exhibit neural phenotypes and ameliorate neurological deficits after grafting into the ischemic brain of rats. Exp Neurol 2002;174:11-20.

54 Bliss TM, Kelly S, Shah AK, Foo WC, Kohli P, Stokes C, Sun GH, Ma M, Masel J, Kleppner SR, Schallert T, Palmer T, Steinberg GK: Transplantation of hNT neurons into the ischemic cortex: cell survival and effect on sensorimotor behavior. J Neurosci Res 2006; 83:1004-1014.

55 Hicks AU, Hewlett K, Windle V, Chernenko G, Ploughman M, Jolkkonen J, Weiss S, Corbett D: Enriched environment enhances transplanted subventricular zone stem cell migration and functional recovery after stroke. Neuroscience 2007;146:31-40. 
56 Zhang L, Li Y, Zhang C, Chopp M, Gosiewska A, Hong K: Delayed administration of human umbilical tissue-derived cells improved neurological functional recovery in a rodent model of focal ischemia. Stroke 2011;42:1437-1444.

57 Kolb B, Morshead C, Gonzalez C, Kim M, Gregg C, Shingo T, Weiss S: Growth factorstimulated generation of new cortical tissue and functional recovery after stroke damage to the motor cortex of rats. J Cereb Blood Flow Metab 2007;27:983-997.

58 Erlandsson A, Lin CH, Yu F, Morshead CM Immunosuppression promotes endogenous neural stem and progenitor cell migration and tissue regeneration after ischemic injury. Exp Neurol 2011;230:48-57.

59 Eckert MA, Vu Q, Xie K, Yu J, Liao W, Cramer SC, Zhao W: Evidence for high translational potential of mesenchymal stromal cell therapy to improve recovery from ischemic stroke. J Cereb Blood Flow Metab 2013;33: 1322-1334.
60 Moskowitz MA, Lo EH, Iadecola C: The science of stroke: mechanisms in search of treatments. Neuron 2010;67:181-198.

61 Lo EH: Degeneration and repair in central nervous system disease. Nat Med 2010;16: 1205-1209.

62 Colbourne F, Corbett D: Delayed and prolonged post-ischemic hypothermia is neuroprotective in the gerbil. Brain Res 1994;654: 265-272.

63 Sale A, Berardi N, Maffei L: Enrich the environment to empower the brain. Trends Neurosci 2009;32:233-239.

64 Clarke J, Langdon KD, Corbett D: Early poststroke experience differentially alters periinfarct layer II and III cortex. J Cereb Blood Flow Metab 2014;34:630-637.

65 Nudo RJ, Milliken GW, Jenkins WM, Merzenich MM: Use-dependent alterations of movement representations in primary motor cortex of adult squirrel monkeys. J Neurosci $1996 ; 16: 785-807$.
66 Carmichael ST: Cellular and molecular mechanisms of neural repair after stroke: making waves. Ann Neurol 2006;59:735-742.

67 Jeffers MS, Hoyles A, Morshead C, Corbett D: Epidermal growth factor and erythropoietin infusion accelerate functional recovery in combination with rehabilitation. Stroke 2014; 45:1856-1858.

68 Janssen H, Ada L, Bernhardt J, McElduff P, Pollack M, Nilsson M, Spratt NJ: An enriched environment increases activity in stroke patients undergoing rehabilitation in a mixed rehabilitation unit: a pilot non-randomized controlled trial. Disabil Rehabil 2014;36:255262.

69 Madinier A, Quattromani MJ, Sjolund C, Ruscher K,Wieloch T: Enriched housing enhances recovery of limb placement ability and reduces aggrecan-containing perineuronal nets in the rat somatosensory cortex after experimental stroke. PLoS One 2014;9: e93121. 